\title{
Successful Broadband Projects in the Public Sector - a Service Innovation Perspective
}

\author{
Bendik Bygstad \\ Norwegian School of IT \\ Oslo, Norway \\ bendik.bygstad@nith.no
}

Gjermund Lanestedt

Scandpower IT AS

Oslo, Norway

gjla@scandpower.no
Jyoti Choudrie

Business School,

University of Hertfordshire, $U K$

jyoti.choudrie@btopenworld.com

\begin{abstract}
The development of national broadband infrastructures has been recognized as an important part of the vision of the information society, as well as of the modernization of the public sector. This paper investigates the relationship between broadband dissemination and service innovation in the public sector.

We ask, what characterizes successful broadband based service innovation projects in the public sector? The research approach is a quantitative survey in a large public broadband diffusion initiative in Norway

The paper offers three conclusions.

First, broadband based service innovation is seen as a two-step process; first a technologically oriented project, followed by an organizational implementation. The focus of the project manager should be on the second of the phases, not the first.

Second, the engagement of a professional external project manager does not support service innovation. The reason is that the external project manager lacks the necessary local knowledge and alliances with central stakeholders.
\end{abstract}

Third, traditional project management is not well suited to understand and manage service innovation.

\section{Introduction}

When the visions of the Information Society were formulated in the US and the European Union in the late 1990s, the lack of national broadband infrastructures was identified as a major obstacle. Different support and roll-out initiatives were adopted in national ICT policy programs and action plans in a number of developed countries, in order to improve the general access to broadband internet connections and thus facilitate the transformation to a digital economy.

One approach has been to stimulate the public sector's innovation and modernization efforts. The rationale has been that more digital co-operation, interactive e-Government applications and other information intensive services to the public will contribute to a significant nation-wide demand for broadband infrastructures - justifying more infrastructure investments and stimulating the market for broadband services. In Scandinavia this approach has shown to be quite successful - giving potential broadband access to the internet for almost all public sector bodies, businesses and a major part of the population [12].

However, infrastructures are means, not ends. The crucial aspects of infrastructures are which actual products and services they enable and support. Having broadband access to the Internet, private service providers as well as public institutions can offer a range of new interactive or media rich services to the public. Thus, the existence of broadband infrastructures is imperative to many e-Government initiatives.

In a recent report for the European Union, a group led by the former Finnish Prime Minister Esko Aho, called for a new approach to innovation in Europe [1]. First, the report argues that the large European public sector should create a market for innovations. Second, it argues that Europe has focused too little on service innovation, where its greatest potential for future growth lies.

Our point of departure is that it is difficult to discuss service innovation in a general context. Both innovations and services include a vast variety of solutions and sectors [19]. Since broadband technology is a powerful enabler of services, we suggest that such projects present an interesting opportunity to study 
technology based service innovation. Our empirical basis is a large public broadband program in Norway.

Our research question is: what characterizes successful broadband based service innovation projects in the public sector?

The remainder of this paper is organized as follows. In section 2 we discuss the concept of service innovation and the challenge of measuring success in IS projects. From this discussion we offer four hypotheses. In section 3 we present the Hoykom programme, and applied research methodology. Section 4 presents the results of the survey and section 5 discuss findings and implications. The last section offers some brief conclusions.

\section{Service Innovation with Broadband Technology}

In contrast to product innovation, technology based service innovation is characterized by the fact that the result of service innovation is not an object. The innovation is the interplay between the providing organization, the new technology and the users [20]. The innovation of internet banking, for example, is not the web interface, but the new interplay between the bank, web technology and bank customers. Therefore, the success of a service innovation is not as much linked to characteristics of the solution, as to the actual use of it.

Bearing this in mind, the question to be determined is: How should ICT-based innovation in the public sector be organized? The answer is usually a combination of central initiatives and local projects. While central initiatives are crucial for the political support and financing of the programs, much of the actual innovation takes place in the local projects. The reason is that service innovation is dependent on close interaction with the users of the service [19], and also that local adaptation of technology is important [16].

\section{Measuring success}

Measuring the success of such projects has proven to be difficult. A number of frameworks have been proposed to measure success:

- $\quad$ The Technology Acceptance Model [8]

- DeLone and McLean's model [9]

- Atkinsons framework [3]

- $\quad$ The CHAOS Report [18]

A key implication of this research is that it is essential to differentiate between the success of the project (in terms of time, cost and product quality) and the organizational impact (in terms of user behavior and business benefits). As Atkinson [3] argues, the link between project success and organizational impact may be weaker than assumed.

Thus, to understand service innovation it is necessary to understand both project success and organizational impact. Specifically, it is important to understand how the different project attributes influence organizational impact.

\section{Hypotheses}

To investigate the relationship between project success and organizational impact, a set of four hypotheses has been developed:

A. Successful organizational impact is associated with great attention to the technological aspects of a project.

B. Successful organizational impact is associated with the use of professional Project Managers.

C. Successful organizational impact is associated with projects that are completed on time, on budget and with satisfying quality.

D. Successful organizational impact is associated with projects containing a detailed project plan over the desired organizational effects.

The first three hypotheses were based on reported results from a growing body of broadband diffusion research in the US [16], Sweden [10], South Korea [6] and Canada [4]. They are also based on general assumptions in IS research [16] and IS Project Management research [5].

The fourth hypothesis was derived from the more general literature on IS implementation success $[8,16]$. It is also supported by broadband research in Sweden [2], which found that without clearly defined new services, broadband infrastructure had less impact.

\section{Methodology}

Our main research approach was a quantitative survey of a high-profile broadband initiative, the Hoykom programme. It is run by the Norwegian Government, as an important part of their action plan eNorway 2009 The Digital Leap - for modernization of the public sector. The programme was initiated in 1999, initially for a period of three years (1999 - 2001), but successively prolonged. It's third and current period of operation runs from 2005 to 2007. The goal of the programme is the development of a coordinated and user-adapted public sector, where the general 
public's interaction with the authorities will be easier, and freeing resources which may strengthen the welfare state. The Hoykom programme plays an important role in the modernization efforts by supporting public sector organizations that wish to offer or utilize broadband intensive e-Government services - within the scope of a time limited project. Nearly 400 ICT projects have been accomplished so far. A majority of them have been conducted by local authorities, but the portfolio also includes projects implementing e-services and digital co-operation at the central governmental level. The programme serves as a provider of examples of successful e-Government implementations and projects that are candidates for extensive roll out. It is also an important instrument in financing and coordinating central and regional e-Government initiatives.

\section{Data Collection}

A questionnaire with 38 questions was designed, on the basis of the four hypotheses. A pilot survey was undertaken in the initial stages in order to determine the suitability and clarity of the questions. The web based questionnaire was mailed to 352 Hoykom project managers and project owners of accomplished projects. 130 responded, which is 37 percent. Non-response bias was investigated in respect of project size, geographic distribution and type of project manager, but not found to be significant.

The questions focused on project attributes and organizational impact. Organizational impact was defined as service innovations: new or improved services, or improved processes to produce the services.

\section{Data Analysis}

First, a descriptive statistical analysis was performed, using SPSS to generate frequencies and cross-tabulations. The results are shown in the next section. Second, to investigate the hypotheses, correlation analysis was deployed, focusing on the relationships between various project attributes and organizational impact.

\section{Qualitative Analysis}

To supplement the quantitative analysis a minor qualitative analysis was undertaken. Two projects that appeared particularly successful (in the survey) were analyzed in detail, using the Hoykom project database as the source. This includes the original applications and the final reports from the projects.

\section{Findings}

Most of the projects were relatively small, with 67 percent having a budget less than $\$ 350.000$.

\section{Descriptive statistics}

Regarding project success the distribution is shown in table 1:

\begin{tabular}{ll} 
High degree of success & $54 \%$ \\
Medium high degree of success & $24 \%$ \\
Medium low degree of success & $17 \%$ \\
Low degree of success & $5 \%$ \\
\hline$-9-100$
\end{tabular}

Table 1: Project success in Hoykom

This result confirmed the general view that Hoykom was a successful program. It showed that most projects achieved their objective within time and budget.

Regarding organizational impact the figures were somewhat less impressive, as shown in table 2 :

\begin{tabular}{lc} 
High organizational impact & $3 \%$ \\
Medium high organizational impact & $20 \%$ \\
Medium low organizational impact & $57 \%$ \\
Low organizational impact & $20 \%$ \\
\hline SUM & $100 \%$
\end{tabular}

\section{Table 2: Organizational impact}

As table 2 shows the majority of the projects were judged to have a medium low or low organizational impact. This illustrates an important point discussed earlier in this paper; that is, service innovation is dependent on more factors than project success. It also reveals that the relationship between project success and organizational impact is more complex than often is assumed [3]. To investigate this aspect correlation analysis was deployed.

\section{Correlation analysis}

The objective of this analysis was to test the four hypotheses mentioned above. The result is shown in table 3. 


\begin{tabular}{|l|c|c|}
\hline \multicolumn{1}{|c|}{ Hypothesis } & $\begin{array}{l}\text { Pearson } \\
\text { corre- } \\
\text { lation }\end{array}$ & $\begin{array}{l}\text { Suppor- } \\
\text { ted? }\end{array}$ \\
\hline $\begin{array}{l}\text { A. Successful organizational impact } \\
\text { is associated with great attention to } \\
\text { the technological aspects of the } \\
\text { project. }\end{array}$ & 0.180 & No \\
\hline $\begin{array}{l}\text { B. Successful organizational impact } \\
\text { is associated with the use of } \\
\text { professional Project Managers. }\end{array}$ & -0.015 & No \\
\hline $\begin{array}{l}\text { C. Successful organizational impact } \\
\text { is associated with projects that are } \\
\text { completed on time, on budget and } \\
\text { with satisfying quality. }\end{array}$ & 0.282 & $\begin{array}{c}\text { Some } \\
\text { support }\end{array}$ \\
\hline $\begin{array}{l}\text { D. Successful organizational impact } \\
\text { is associated with projects with a } \\
\text { detailed project plan over the desired } \\
\text { organizational effects. }\end{array}$ & 0.659 & Yes \\
\hline
\end{tabular}

Table 3: Results of correlation analysis

As table 3 illustrates there is no support for the first two hypotheses and weak support for the third. For the fourth hypothesis there is relatively strong support in the collected data.

\section{Discussion}

Our research approach is based on the analytical distinction between a successful project and its organizational impact. Broadband based service innovation is seen as a two-step process; first, a technologically oriented project, followed by an organizational implementation. This sequence is well known from traditional IS implementation research [8, 16]. The distinction is illustrated in table 4. Project success is the responsibility of the project manager, who is assessed on his ability to reach the target on time, on budget and on quality. Focus for the project manager is the availability of the new service. In contrast, the organizational impact is the responsibility of the CEO or line manager. The success criteria are the acceptance and use of the service by the user community.

\begin{tabular}{|l|l|l|}
\hline & Project success & $\begin{array}{l}\text { Organizational } \\
\text { impact }\end{array}$ \\
\hline Responsible & Project Manager & $\begin{array}{l}\text { CEO } \\
\text { Line Manager }\end{array}$ \\
\hline $\begin{array}{l}\text { Success } \\
\text { criteria }\end{array}$ & $\begin{array}{l}\text { Time, budget, } \\
\text { quality }\end{array}$ & Acceptance and use \\
\hline Focus & $\begin{array}{l}\text { Availability of } \\
\text { service }\end{array}$ & $\begin{array}{l}\text { Use and impact of } \\
\text { service }\end{array}$ \\
\hline
\end{tabular}

Table 4: Project success and organizational impact
This distinction is even more important in service innovation than in product innovation, because an unused product may still have some value, while an unused service does not.

Returning to our hypotheses, we will now assess the findings presented in section 4 .

The first hypothesis assumed that successful organizational impact is associated with great attention to the technological aspects of the project.

From table 3 it can be learnt that the Pearson corelation result was weak, thus suggesting that successful organizational impact is not associated to the technological aspects of a project. While attention to technology is obviously a necessary factor for success [13], a strong focus on technology was not associated with service innovations. However, this finding should not be misinterpreted. In our research most project managers were IT professionals, thus the technology aspect of the projects were well taken care of in most cases.

The second hypothesis assumed that successful organizational impact is associated with the use of professional project managers.

Our findings (-0.015 in table 3) did not support this hypothesis. Successful service innovation could not be explained by the use of an external professional project manager, and neither by the use of an internal project manager. We interpret this finding as strengthening the argument summarized in table 4 . What makes the external project manager a professional is his/her ability to deliver the project on time, cost and quality [5]. However, the success criterion of service innovations is the acceptance and actual use of the service. The external project manager does not possess any particular skill to achieve this; rather it can be argued that a lack of local knowledge and authority may represent a barrier in this capacity.

The third hypothesis assumed that successful organizational impact is associated with projects that are completed on time, on budget and with satisfying quality.

Our findings (0.282) indicate some support for this hypothesis, but the association is not very strong. Some projects may be successful, but organizational impact is low. Vice versa unsuccessful projects (in terms of cost, time and quality) may lead to successful service innovations

We think this finding illustrates our main argument: a successful project result is a necessary condition for a successful service innovation, but it is not a sufficient one. Rather, a very strong focus on the project results (time, cost, quality) may represent a barrier to service innovation. The reason is that innovation processes to a 
certain extent are emergent and nonlinear, and incongruent with strong time and cost pressures [7].

The fourth hypothesis assumed: Successful organizational impact is associated with projects that have a detailed project plan over the desired organizational effects. This hypothesis was strongly supported.

How should we interpret this finding? Does it suggest that if you plan for organizational success you will achieve it? Unfortunately, our materials could not provide an answer to this question. Therefore, we conducted a small quantitative analysis.

\section{Two successful cases}

From the quantitative analysis two projects having a maximum score on both organizational success (impact) and on planning organizational change were identified. Both projects were from the west coast of Norway.

The first was "Community network of the Nordfjord district - Regional broadband dissemination based on co-operation among seven municipalities". The project's objective was to implement digital public services (i.e. video casts from the municipalities' executive board meetings, GIS- and map services, interactive library services) in all of the seven municipalities - based on a coordinated and secure common infrastructure and a model of mutual ICT service hosting. The second was the establishment of a joint 24/7 medical service facility, based on telemedicine solutions, for several small communities in another sparsely populated area of western-Norway.

Analyzing the plans of the two projects, the following attributes appeared.

The two projects had obviously been given much attention from local politicians, employees and users regarding the problems to be tackled, and the actual project plans and ambitions. They had very clear objectives as they could be considered as responses to resource shortage challenges (competence and money) - forcing small communities in rural districts to cooperate to uphold a certain public service level. The planning documents addressed these issues explicitly.

Further, the project plans focused on:

- Organizational and contextual matters, without compromising on technology issues

- The actual organizational impact of the technology, not just in general but to some detail (i.e. impact on established work routines, work flow and necessary process redesign)
- The involvement of users and all stakeholders in preparatory phases, in strategy processes and important decision points

- Risk factors concerning organizational matters (like competence demands, need of systematic usability tests of services)

\section{Summarizing findings}

First, planning for organizational success implies that the project manager is aware of the complex range of organizational issues confronting him/her. In broadband based service innovation projects this includes a strong understanding of the problem or needs that the service will address, the identification of key users, and clear boot-strap tactics. The boot-strap tactics refer to the mechanism that enrolls the early users in order to create a critical mass of use [11].

Second, planning for organizational success presupposes that the project manager is able to build alliances with key stakeholders in order to ensure that the service is successfully adopted. Key stakeholders are certainly the users, but in a public broadband context they also include line managers, cooperative municipalities and other government agencies.

These issues explain the negative findings of the first three hypotheses. They explain why a strong technological focus is inadequate because service innovation is about the interplay between technology, organization and users $[16,18]$. They also explain why an external project manager does not help, since organizational knowledge is a key factor for innovation success. What is also enlightened is why a predominantly internal project focus has clear limitations; that is, the real innovation is mainly organizational.

\subsection{Implications for practice}

What do these findings imply for service innovation management in the public sector?

We argue that our findings indicate that broadband based service innovation projects should focus on the organizational implementation process, and not the technological aspects. The reasoning for this is described above. It is however important to bear in mind that the project manager should understand the technology in depth.

This raises another issue. Traditional project management focuses on cost, time and quality [5]. The findings in this research indicate that this focus is not effective, and may be even harmful, to technology based service innovation. Service innovation was found 
to be dependent on the understanding of a complex range of organizational issues, and of the enrollment of key stakeholders. This is hardly congruent with a strict project schedule, and project initiators should seek other mechanisms for control.

One can take this a step further, questioning whether project organization is the appropriate tool for service based innovation. Considering our findings, we think the public sector would benefit from experimenting with alternative methods and approaches in their modernization and service innovation efforts. A key issue is to ensure the commitment of line managers and ownership by line users in the innovation process.

\section{Conclusions}

The development of national broadband infrastructures has been recognized as an important part of the vision of the information society, as well as of the modernization of the public sector. This paper investigated the relationship between broadband and service innovation in the public sector

The study used a national broadband initiative in Norway, Hoykom, as a case to identify the critical success factors pertinent for the successful broadband based service innovation in the public sector.

Utilizing literature from the broadband diffusion and information systems areas four hypotheses were formed and tested. From the results, only one of the four was supported by this research. This hypothesis was that successful service innovation is associated with projects with a detailed project plan over the desired organizational effects.

The paper offers three conclusions.

First, broadband based service innovation is seen as a two-step process; first a technologically oriented project, followed by an organizational implementation. The focus of the project manager should be on the second of the phases, not the first. The reason is that service innovation is basically an organizational process, not a technological one.

Second, the engagement of a professional external project manager does not support service innovation. The reason is that the external project manager lacks the necessary local knowledge and alliances with central stakeholders.

Third, traditional project management is not well suited to understand and manage service innovation. Project management usually focuses on internal issues such as time, cost and quality, while the successful service innovation projects have a clear organizational focus. Thus, public organizations would benefit from experimenting with alternative approaches, different from traditional project management, in their modernization efforts.

\section{Limitations and further research}

There are certainly limitations to this research. Our interest in this study was to determine the role of broadband as an enabler for service innovation. The conclusions are not relevant for broadband initiatives that focus on infrastructure, and neither for centralized roll-out initiatives. The field of service innovation is a complex one, and the data was limited to broadband enabled service innovation projects in the public sector. It is not claimed that the findings of this research are valid outside this context.

Further directions for this research lie in studying technology based service innovation in the public sector within other contexts, and applying other technologies. There could also be an in-depth assessment of the interplay between central initiatives and local innovation and to investigate their impact on service innovations.

\section{Acknowledgements}

The three anonymous reviewers of HICSS provided valuable comments to improve the paper. We also thank Thomas Slette for his work on the Hoykom data.

\section{References}

[1] Aho, E. (2006). Creating an Innovative Europe, The European Commission.

[2] Aronsson, M. et al. (2003). "Broadband services for residential and commercial tenants: a categorisation of current and future services and a survey on tenants needs in Sweden." Building and Environment 38(2): 347-358.

[3] Atkinson, R. (1999). "Project management: cost, time and quality, two best guesses and a phenomenon, its time to accept other success criteria." International Journal of Project Management 17(6): 337-342.

[4] Broadband Pilot Program Office (2006). Broadband Canada. http://broadband.gc.ca/pub/program/bbindex.html, Accessed June 10, 2006

[5] Cadle, J. and D. Yeates (2004). Project Management for Information Systems. Harlow, Prentice-Hall.

[6] Choudrie, J. and H. Lee (2002). Investigating broadband technology deployment in South Korea. Report of BrunelDTI International Technology Services Mission To South Korea. Uxbridge, Brunel University. 
[7] Ciborra, C. (2000). From Control to Drift. Oxford, Oxford University Press.

[8] Davis, F. (1989). "Perveived Usefulness, Perceived Ease of Use, and User Acceptance of Information Technology." MIS Quarterly 13:3: 319-340.

[9] DeLone, W. H. and E. R. McLean (1992). "Information Systems Success: The Quest for the Dependent Variable." Information Systems Research 3(1): 60-95.

[10] Granholm, A. (2000). The Swedish commitment to broadband both in the cities and in the countryside. The Ministry of Industry, Employment and Communication. http://www.oecd.org/dataoecd/25/27/2736714.pdf

[11] Hanseth, O. and K. Lyytinen (2004). "Theorizing about the Design of Information Infrastructures: Design Kernel Theories and Principles." Sprouts: Working Papers on Information Environments, Systems and Organizations 4(Fall 2004): Article 1.

[12] Hansteen, K. (2006). Norwegian and Swedish Broadband Initiatives 1999-2005. Oslo, Norwegian Research Council.

[13] Hong, K.K. and Kim, Y.G. (2001). The Critical Success Factors for ERP Implementation: An Organizational Fit Perspective. Information and Management., 40:25-40.
[14] Laudon, C. K. and J. P. Laudon (2004). Management Information Systems. Upper Saddle River, New Jersey, Pearson Education.

[15] Leonard-Barton, D. (1988). " Implementation as Mutual Adaptation of Technology and Organization." Research Policy 17:5: 251-267.

[16] Markus, M. L., Keil, M. (1994). " If We Build it, They Will Come: Designing Information Systems That People Want To Use." Sloan Management Review 35(4).

[17] MCGinity, M. (2003). "Power to the people." Communication of the ACM 46(9).

[18] Standish Group (2001). Extreme Chaos. http://www.standishgroup.com/chaos_resources/index.php, Accessed June 10, 2006

[19] Tether, B. S. and J. S. Metcalfe (2004). Services and systems of innovation. Sectoral Systems of Innovation Concepts. Issues and Analyses of Six Major Sectors in Europe. F. Malerba, Cambridge University Press.

[20] Tidd, J. and F. M. Hull (2003). Service Innovation. Organizational Responses to Technological Opportunities \& Market Imperatives. London, Imperial College Press. 